\title{
Starter cultures and cattle feed manipulation enhance conjugated linoleic acid concentrations in Cheddar cheese
}

\author{
M. S. Mohan, ${ }^{1}$ S. Anand, ${ }^{2}$ K. F. Kalscheur, A. N. Hassan, and A. R. Hippen \\ Midwest Dairy Foods Research Center, Dairy Science Department, South Dakota State University, Brookings 57007
}

\begin{abstract}
Conjugated linoleic acid (CLA) is a fatty acid (FA) that provides several health benefits to humans. The feeding of fish oil-supplemented diets to dairy cows has been extensively studied as a means to improve the CLA content in milk. Several studies have also been conducted on the ability of many microorganisms to produce CLA by utilizing substrates containing linoleic acid. In the present study, the dietary manipulated milk was used in combination with the CLA-producing culture to manufacture Cheddar cheese. The two diets fed to cattle were control and treatment diets to obtain control and treatment milk, respectively. The treatment diet containing fish oil ( $0.75 \%$ of dry matter) was fed to 32 dairy cows grouped in a pen for $18 \mathrm{~d}$ to increase the total CLA content in milk. Treatment milk had a CLA content of $1.60 \mathrm{~g} / 100 \mathrm{~g}$ of FA compared with $0.58 \mathrm{~g} / 100 \mathrm{~g}$ of FA in control milk obtained by feeding the control diet. A $2 \times 2$ factorial design with 3 replicates was used to test the combined effect of the CLA-producing starter culture of Lactococcus lactis (CI4b) versus a commercial CLA nonproducing cheese starter as the control culture, and type of milk (control vs. treatment milk) on CLA content in Cheddar cheese. Chemical composition (moisture, salt, fat, and protein) was not affected by the type of culture used. However, the age of the cheese affected the sensory properties and microbiological counts in the different treatments. Ripening with the CI4b culture was found to be effective in further enhancing the CLA content. The CI4b cheeses made from control milk and treatment milk contained 1.09 and $2.41( \pm 0.18) \mathrm{g}$ of total CLA/100 g of FA after 1 mo of ripening, which increased to 1.44 and $2.61( \pm 0.18) \mathrm{g}$ of total CLA/100 g of FA after 6 mo of ripening, respectively. The use of treatment milk resulted in an increase in the CLA isomers (trans-7, cis-9 + cis-9,trans-11, trans-9, cis- $11+$ cis-10,trans- 12 , trans-
\end{abstract}

Received August 29, 2012.

Accepted December 21, 2012.

${ }^{1}$ Present address: Department of Food Science and Technology, University of Tennessee, Knoxville 37996.

${ }^{2}$ Corresponding author: sanjeev.anand@sdstate.edu 10,cis-12, cis-9,cis-11, trans-11,cis-13, cis-11,cis-13, trans-11,trans-13, and trans-9,trans-11). The CI4b culture specifically increased cis-11, cis-13 and trans10,cis-12 isomers in cheese. The total CLA content in cheese was significantly higher when the CI4b culture was used compared with CLA nonproducing culture cheeses made from control milk and treatment milk after $1 \mathrm{mo}$ [1.09 and $2.14( \pm 0.18) \mathrm{g}$ of total CLA $/ 100$ $\mathrm{g}$ of FA] and 6 mo [0.99 and $2.05( \pm 0.18) \mathrm{g}$ of total CLA/100 g of FA] of ripening, respectively. The results indicated that the combination of a CLA-producing starter culture and milk from cattle fed fish oil-supplemented diets (0.99 g of CLA/100 g of FA) could enhance levels of total CLA in Cheddar cheese by up to 2.6 times compared with cheese made from control milk with CLA nonproducing starter culture $(2.61 \mathrm{~g}$ of CLA/100 g of FA) after 6 mo.

Key words: fish oil, Lactococcus, conjugated linoleic acid, cheese

\section{INTRODUCTION}

Conjugated linoleic acid (CLA) is a collective term for all the positional and geometric isomers of linoleic acid. The different CLA isomers are associated with several health benefits, such as anticarcinogenic, antioxidant, antidiabetic, antiatherosclerosis, and immune modulation benefits (Benjamin and Spener, 2009). Isomers cis-9,trans-11 CLA and trans-10,cis-12 CLA are considered to be the most important isomers of CLA associated with health benefits. Major sources of CLA in the human diet are ruminant meat and dairy products. Milk, cheese, and fermented dairy products contain total CLA of about 0.41 to $0.55,0.40$ to 1.70 , and 0.30 to $0.50 \mathrm{~g} / 100 \mathrm{~g}$ of FA, respectively (Chin et al., 1992; Shantha et al., 1995; Mushtaq et al., 2010).

Conjugated linoleic acid in milk is preformed in the rumen of cattle as an intermediary in the microbial hydrogenation of PUFA. Several studies have shown that feeding fish oil to cattle increases the CLA content in milk (Donovan et al., 2000; Shingfield et al., 2012). Addition of fish oil $(2 \% \mathrm{DM})$ to cattle diets also increased the CLA content in milk up to $2.07 \mathrm{~g} / 100 \mathrm{~g}$ of FA compared with $0.60 \mathrm{~g} / 100 \mathrm{~g}$ of FA in control milk 
(Whitlock et al., 2002). Donovan et al. (2000) proposed that fish oil acts as a rumen modifier to stimulate the production of additional CLA from linoleic acid present in the other feed materials. Cheddar cheese manufactured from enhanced CLA milk (4.8 times increase in CLA compared with control milk) obtained by dietary manipulation of cattle was found to have higher CLA content of $1.93 \mathrm{~g} / 100 \mathrm{~g}$ of FA compared with control cheese containing $0.78 \mathrm{~g} / 100 \mathrm{~g}$ of FA (Coakley et al., 2007).

Apart from rumen bacteria, several lactic acid bacteria have also been shown to produce CLA (Ogawa et al., 2005; Rodríguez-Alcalá et al., 2011). Most of the studies on production of CLA by food-grade bacteria utilize linoleic acid-rich oils as substrates (Andrade et al., 2012). In a previous study in our laboratory, a CLA-producing starter culture of Lactococcus lactis (CI4b) was identified, which increased the total CLA content from 0.41 to $1.21 \mathrm{~g} / 100 \mathrm{~g}$ of $\mathrm{FA}$ in fermented milk without the addition of any substrates (Pandit et al., 2012). The CI4b culture was also found to possess good starter culture activity for cheese manufacture. The CI4b starter increased the CLA content of Cheddar cheese from 0.61 to $0.97 \mathrm{~g} / 100 \mathrm{~g}$ of FA (Pandit, 2008).

The health benefits of CLA have been known for more than 3 decades. Consequently, efforts have been made to increase the CLA content in milk and milk products. Despite these efforts, the estimated dietary intake of CLA in human diet remains very low compared with the dosage required for rendering the health benefits. Huth and group (2006) have quoted up to $0.42 \mathrm{~g}$ of $\mathrm{CLA} / \mathrm{d}$ as the effective dosage for anticarcinogenic effects in human beings. Fortification with commercially available CLA isomers, which could have been the most efficient method of enhancing CLA content in dairy products, however, is associated with many disadvantages. Fortification techniques have been associated with off-flavors in the final products (Campbell et al., 2003). The CLA isomer composition in such fortified products is different from the naturally available isomer compositions in food products. Dietary manipulation and use of CLA-producing cultures increases the CLA content in milk and milk products considerably (Donovan et al., 2000; Ogawa et al., 2005). Although these methods have been studied individually, to our knowledge no studies have been reported combining these 2 methods to further enhance the CLA content in dairy products. We, therefore, hypothesized that the use of CLA-enhanced milk produced through dietary manipulation in combination with a starter culture producing CLA to manufacture Cheddar cheese would further enhance the CLA content of cheese compared with the individual treatments. This could, in turn, provide the amount of CLA in the diet required for conferring health benefits. Our specific objective was to further enhance the CLA content in Cheddar cheese by using milk obtained by dietary manipulation by feeding fish oil to dairy cows and by using CI4b culture, in combination.

\section{MATERIALS AND METHODS}

\section{Dietary Manipulation of Cattle for Enhancement of CLA in Milk}

Dietary manipulation of cattle was done by feeding the cattle with diets supplemented with fish oil at the Dairy Research and Training Facility at South Dakota State University (Brookings). The control diet consisted of concentrates and forage in the ratio of 47:53. The concentrate portion consisted of $13.1 \%$ soybean meal, $14.7 \%$ corn (high-moisture shelled), $3.2 \%$ dried distillers grains with solubles, $4.8 \%$ fuzzy cottonseed, $3.8 \%$ beet pulp, $2.2 \%$ sugar, $1.1 \%$ rumen-inert fat, and $3.6 \%$ vitamin and mineral supplements, whereas the forage portion consisted of $11.4 \%$ alfalfa hay, $4.9 \%$ alfalfa haylage, $4.6 \%$ ground shell corn, and $32.5 \%$ corn silage. The treatment diet was the control diet supplemented with Menhaden fish oil (Omega Protein Inc., Hammond, LA) at $0.75 \%$ of the diet DM. The control and treatment diets were fed to 32 dairy cows grouped in a pen. The control diet feeding was started 1 mo before the feeding of the treatment diet. The treatment diet was fed for a period of $18 \mathrm{~d}$, as Whitlock et al. (2002) observed that the maximum yield of CLA in milk occurs during this period. The feed samples for both control and treatment diets were collected during this period on $\mathrm{d} 7$, 10 , and 17 and stored at $-20^{\circ} \mathrm{C}$ until further analysis. The chemical composition (DM, CP, and NDF) of the 2 diets was similar. The supplementation of $0.75 \%$ (by DM) fish oil to the control diet increased the DM to $56.9 \%$ in the treatment diet compared with $55.6 \%$ in the control diet. The treatment diet had CP and NDF contents of 18.3 and $27.7 \%$ of DM, respectively. This was similar to the control diet with CP being $18.3 \%$ of DM and NDF being $30.4 \%$ of DM.

The milk obtained after feeding fish oil (treatment diet) was termed treatment milk. Control milk was obtained from feeding the control diet. Both types of milk were collected on the respective day of cheese making.

\section{Feed Composition Analysis}

The frozen feed samples were thawed and dried at $55^{\circ} \mathrm{C}$ in an oven (style V-23; Despatch Oven Co., Minneapolis, MN) for $48 \mathrm{~h}$. The dried samples were then ground to pass through a 2-mm screen of a Wiley mill 
(model 3; Arthur H. Thomas Co., Philadelphia, PA) and then reground through a $1-\mathrm{mm}$ screen of an ultracentrifuge mill (Brinkman Instruments Co., Westbury, $\mathrm{NY})$, and analyzed for $\mathrm{DM}\left(105^{\circ} \mathrm{C}\right.$ for $\left.4 \mathrm{~h}\right), \mathrm{NDF}$ with addition of sodium sulfite, and heat-stable $\alpha$-amylase during extraction (Ankom $^{200}$ fiber analyzer; Ankom Technology Corp., Fairport, NY; Van Soest et al., 1991), CP (automated N combustion analyzer; Elementar Analysensysteme GmbH, Hanau, Germany; AOAC International, 2006; method 968.06). The DM and CP contents were calculated as averages of the 3 replicates of feed samples from 3 different days of feeding. The NDF and CP contents were expressed as DM percentages.

\section{Cheddar Cheese Manufacture and Ripening}

Cultures and Sources. Two different cultures were used for cheese making, a CLA-producing culture and a CLA nonproducing culture. The CLA-producing culture (CI4b) was isolated from cheese in our laboratory (Pandit, 2008). The CLA nonproducing culture was a commercially available direct vat set (DVS) cheese culture, DVS 850 (Chr. Hansen Inc., Milwaukee, WI), consisting of Lactococcus lactis ssp. lactis and Lactococcus lactis ssp. cremoris.

The Cheddar cheese-making treatments were designed as a $2 \times 2$ factorial experiment to test the effect of culture (DVS vs. CI4b) and type of milk (control vs. treatment milk). Direct vat set and CI4b cultures were propagated as bulk culture with $2 \%$ rate of inoculation (Pandit, 2008). Cheddar cheese was manufactured at the South Dakota State University (SDSU) Dairy Plant (Brookings). Each batch of cheese was manufactured from $110 \mathrm{~kg}$ of cheese milk, using double-O Cheese vats (Kusel Equipment Co., Watertown, WI). The raw milk was pasteurized and then standardized to fat content of $3.4 \%$ by addition of cream or skim milk separated from the same lot of milk using a cream separator (model no. 392; Separators Inc., Indianapolis, Indiana). Cheddar cheese was manufactured by the method described by Awad et al. (2005a). Chymosin at the rate of 8.5 mL/100 kg (Chy-Max; Chr. Hansen Inc.) was added to cheese milk for coagulation. Curd after milling was salted at $2 \%$ salt by weight of cheese curd in 2 equal applications at 5-min intervals. Salted curd was hooped (approximately $11 \mathrm{~kg}$ in each hoop) and pressed overnight at $4 \mathrm{~kg} / \mathrm{cm}^{2}$. On removal of the cheese block from the hoop, it was vacuum packed, dipped in hot water (approx. $80^{\circ} \mathrm{C}$ ), and allowed to ripen at $4^{\circ} \mathrm{C}$. The 4 different types of cheeses were prepared in triplicate.

Cheddar Cheese Ripening Study. Each block was ripened for $1 \mathrm{mo}$ at $4^{\circ} \mathrm{C}$ and then divided into 12 equal parts, resealed by vacuum packaging, and labeled from
1 to 12 for further ripening. Three cheese blocks each were analyzed at 1,3 , and 6 mo of ripening.

Cheddar Cheese Composition. The cheese samples were analyzed for moisture, fat, salt, and total protein by a modified oven method using a forced-draft oven (method 15.111; Hooi et al., 2004), Mojonnier method (method 15.086; Hooi et al., 2004), chloride analyzer (model 926; Nelson Jameson Inc., Marshfield, WI), and micro-Kjeldahl method (method 15.131; Hooi et al., 2004), respectively. The $\mathrm{pH}$ of cheeses was measured at 1, 3, and $6 \mathrm{mo}$ as described by Awad et al. (2005a).

Cheddar Cheese Microbiology. Microbiological counts of cheese samples were obtained for lactic acid bacteria on de Man, Rogosa, and Sharpe (MRS) and M17 agars. Shredded cheese samples (11 g) were homogenized with $99 \mathrm{~mL}$ of $2 \%$ sodium citrate buffer solution in a Seward Stomacher Circulator 400 (Seward Ltd., Norfolk, UK) at $260 \mathrm{rpm}$ for $2 \mathrm{~min}$ at room temperature and serially diluted using $0.05 \%$ peptone water. The dilutions were then surface plated $(0.1 \mathrm{~mL})$ on MRS and M17 plates. The M17 plates were then incubated at $30^{\circ} \mathrm{C}$ aerobically for $48 \mathrm{~h}$ for Lactococcus counts and MRS plates anaerobically (in a gas jar with Mitsubishi AnaeroPack; Mitsubishi Gas Chemical America Inc., New York, NY) at $37^{\circ} \mathrm{C}$ for $48 \mathrm{~h}$ for Lactobacillus counts.

Cheddar Cheese Sensory Evaluation. The cheese samples were evaluated for acid, bitter, unclean, flat/ lacking, and overall flavor, and crumbly, short, curdy, smooth, and overall body and texture attributes. An expert panel study with 6 panelists experienced in evaluating cheese was conducted for grading the coded cheese samples of 3 and 6 mo of age, as described by Awad et al. (2005b). The cheeses produced within a proximity of $10 \mathrm{~d}$ were grouped together to be evaluated on the same day for each ripening period. Two pieces of each cheese sample $(3 \times 1.5 \times 1.5 \mathrm{~cm})$ were randomly presented to the panelists in identical plastic sample cups sealed with plastic lids and identified by a random 3-digit number. The attributes including flavor and body and texture were recorded on a 9-point hedonic scale with flavor and body and texture scores of 1 $=$ none, $5=$ definite, and $9=$ pronounced, and overall flavor and body and texture scores of $1=$ poor, $5=$ average, and $9=$ excellent.

\section{FA Profile Analysis}

Extraction of Fat from Cheese and Milk. The fat was extracted from the cheese sample using the method described by Coakley et al., (2007). Grated cheese samples (15 g) were mixed with $30 \%$ (wt/vol) freshly prepared ammonium thiocyanate solution (25 
$\mathrm{g}$ ), incubated for $1 \mathrm{~h}$ at $60^{\circ} \mathrm{C}$ in a water bath and later centrifuged at 2,800 $\times g$ (Sorvall RC-2 Superspeed Refrigerated Centrifuge; DuPont Co., Wilmington, DE) for $20 \mathrm{~min}$. The centrifuged samples were then frozen overnight and later 15 to $20 \mathrm{mg}$ of the top cream layer was transferred into culture tubes $(13 \times 100-\mathrm{mm}$ size with screw caps) for FA extraction. The fat was extracted from milk samples by centrifugation at $806 \times g$ for $20 \mathrm{~min}$ at $4^{\circ} \mathrm{C}$. Using a thin spatula, 15 to $20 \mathrm{mg}$ of the top cream layer was then weighed into culture tubes $(16 \times 125-\mathrm{mm}$ size with screw caps $)$ for FA extraction.

Fat cakes collected in the culture tubes were further butylated according to the method described by Abdelqader et al. (2009). Briefly, fat cake was treated with $n$-butanol $(750 \mu \mathrm{L})$ and $25 \mu \mathrm{L}$ of internal standard $(10$ $\mathrm{mg}$ of $\mathrm{C} 13: 1 / \mathrm{mL}$ ) and vortexed thoroughly after each step. Acetyl chloride $(75 \mu \mathrm{L})$ was added while vortexing at low speed to the mixture and then the tubes were tightly capped after flushing with nitrogen gas for 2 to $4 \mathrm{~s}$. Tubes were then placed on a $100^{\circ} \mathrm{C}$ heating block for $90 \mathrm{~min}$, after which they were cooled to room temperature. Freshly prepared $6 \% \mathrm{~K}_{2} \mathrm{CO}_{3}(5 \mathrm{~mL})$ was then added to the tubes and the sample vortexed thoroughly for $30 \mathrm{~s}$. This was followed by addition of hexane (1 $\mathrm{mL}$ ), vortexing for $20 \mathrm{~s}$, and centrifugation at $2,800 \times g$ for $20 \mathrm{~min}$. The bottom layer was then discarded using Pasteur pipettes; the top layer was washed with distilled water $(5 \mathrm{~mL})$ and vortexed thoroughly. Washing was done 4 times and each time followed by centrifugation at $2,800 \times g$ for $20 \mathrm{~min}$ and removal of the bottom layer using Pasteur pipettes. After the final washing step, the top layer was transferred (using Pasteur pipettes) into the injection vials for gas chromatographic analysis. The samples were then stored at $4^{\circ} \mathrm{C}$ until analysis.

FA Analysis by Gas Chromatography. All samples prepared as butyl esters were analyzed using gas chromatograph equipped with a flame-ionization detector and autoinjector (model 6890N; Agilent Technologies Inc., Santa Clara, CA). Fatty acids were separated using an SP-2560 fused silica capillary column (Supelco Inc., Bellefonte, PA; dimensions: $110 \mathrm{~m} \times 0.25 \mathrm{~mm}$ $\times 0.2-\mu \mathrm{m}$ film thickness). The split ratio used at the injection port was $30: 1$, with helium as the carrier gas $(1 \mathrm{~mL} / \mathrm{min})$. The injector and detector temperatures were set to be 230 and $250^{\circ} \mathrm{C}$, respectively. The column temperature was held at $50^{\circ} \mathrm{C}$ for 1 min after injection, then increased at $5^{\circ} \mathrm{C} / \mathrm{min}$ to $145^{\circ} \mathrm{C}$, held at $145^{\circ} \mathrm{C}$ for $30 \mathrm{~min}$, further increased at $10^{\circ} \mathrm{C} / \mathrm{min}$ to $190^{\circ} \mathrm{C}$, and held at that temperature for $30 \mathrm{~min}$. Finally, the temperature was raised to $210^{\circ} \mathrm{C}$ at the rate of $5^{\circ} \mathrm{C} / \mathrm{min}$ and held at this temperature for $40 \mathrm{~min}$. Sample analysis on the gas chromatograph was outsourced to SGS MidWest Seed Services Inc. (Brookings, SD). Individual FA were identified by order of elution and comparison to a combined standard (prepared by compiling together reference standards GLC-606 and GLC-566; Nu-Chek Prep Inc., Elysian, MN). The reference standards mixtures were dissolved with $n$-butanol to $10 \mathrm{mg} / \mathrm{mL}$ concentration $(750 \mu \mathrm{L})$ and were also subjected to the FA extraction procedure used for cheese samples (without further addition of $n$-butanol).

In the case of CLA isomers, the peaks were identified using commercial standards (Matreya catalog no. 1245, 1247, 1249, and 1259; Matreya LLC, Pleasant Gap, PA) based on the retention time for each peak. The order of elution (shown in Figure 1) was confirmed from the gas chromatographs published for CLA isomers in earlier studies (Sehat et al., 1998; Eulitz et al. 1999; Kramer et al., 2004). The ratios of the area under each FA peak and the calculated actual concentration of the FA are termed as the concentration factors. The reference standards (GLC-606 and GLC-566; Nu-Chek Prep Inc.) used for compiling the combined standard did not contain the array of CLA isomers observed in the milk and cheese samples. Hence, the cis-9,trans-11 CLA isomer peak from the reference standard was broken down in the same ratio as the different CLA isomers in the milk and cheese samples. This enabled the calculation of the concentration factor associated with each CLA isomer (modified from the method used by Abdelqader et al., 2009):

Area under ith CLA isomer peak in combined standard $\left(\right.$ Ref. CLA area $\left.{ }_{i}\right)=$ Ref. CLA peak area

$\times$ peak area of $i$ th CLA isomer in sample /

Total peak area for all CLA isomer peaks in sample;

Concentration factor for $i$ th CLA isomer $=$

Ref. CLA area ${ }_{i}$ / Concentration (as mg/0.75 mL),

where Ref. $=$ reference.

\section{Statistical Analysis}

Statistical analysis of all data was done using PROC MIXED of SAS (SAS Institute Inc., Cary, NC; 2003) in a completely randomized design. Data for all parameters with different ripening periods for cheese including FA profile, microbiological analysis, and sensory evaluation were analyzed as a $2 \times 2$ factorial model having a split plot with time as the subplot. The model used was $\mathrm{Y}=$ milk + culture $+($ milk $\times$ culture $)+$ month $+($ month $\times$ milk $)+($ month $\times$ culture $)+($ month $\times$ milk $\times$ culture). Data from milk FA analysis was analyzed as a 2 -treatment model of control milk and treatment milk. 


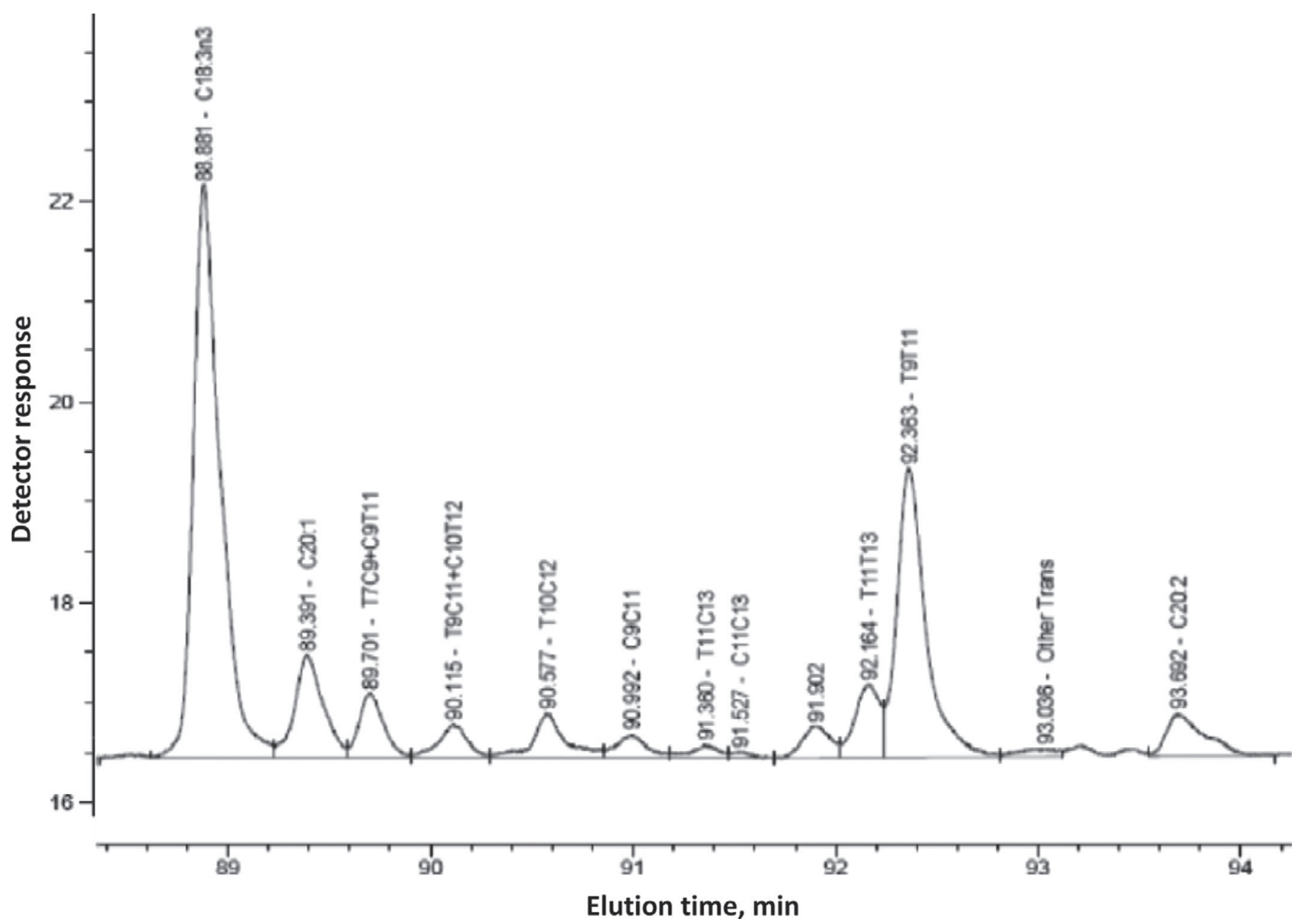

Figure 1. Elution order of conjugated linoleic acid (CLA) isomers in cheese samples. The CLA isomer peaks in the order of elution: trans7,cis-9 + cis-9,trans-11 CLA (T7C9+C9T11), trans-9,cis-11 + cis-10,trans-12 CLA (T9C11+C10T12), trans-10,cis-12 CLA (T10C12), cis9,cis-11 CLA (C9C11), trans-11,trans-13 CLA (T11T13), trans-9,trans-11 CLA (T9T11), and other trans CLA isomers (Other Trans).

Data from Cheddar cheese chemical composition were analyzed as a $2 \times 2$ factorial model using the model $\mathrm{Y}$ $=$ milk + culture $+($ milk $\times$ culture $)$. Differences in all experiments were considered significant at $P \leq 0.05$.

\section{RESULTS AND DISCUSSION}

\section{Milk FA Composition}

Table 1 shows that the total milk fat in control milk (3.59\%) was higher than in treatment milk (3.28\%). This reduction could be associated with the milk fat depression associated with feeding fish oil-supplemented diets to cattle, as reported by other researchers (Donovan et al., 2000). The cis-9,trans-11 CLA isomer (along with the trans-7,cis-9 CLA isomer) peaked with 0.021 and $0.111 \mathrm{~g} / 100 \mathrm{~g}$ of FA in control and treatment milks, respectively, contributing to 3.6 to $6.9 \%$ of the total CLA content. The trans-10,cis-12 CLA isomer contributed 18 to $20 \%$ of total CLA in the control and treatment milk samples. Many authors have reported that cis-9,trans-11 CLA is the major component (82 to $98 \%$ ), with trans-10,cis-12 CLA being the second major component (2 to $14 \%$ ), of total CLA content in milk (Whitlock et al., 2002; Bharathan et al., 2008). However, these studies did not report the presence of coeluted peaks as observed in the present study. Variations in the isomeric profile in standards as well as product samples have also been reported earlier (Kramer et al., 1999). All these indicate that many of the studies conducted lack uniformity and clarity about the order of elution and magnitude of various isomers of CLA. In consideration of these issues, identification of isomers in the present study, however, was done by using CLA isomer standards and published gas chromatographs of milk (Sehat et al., 1998; Eulitz et al., 1999; Kramer et al., 2004). All the CLA isomeric 
Table 1. Average raw milk FA profile of control and treatment milks ${ }^{1}$

\begin{tabular}{|c|c|c|c|c|}
\hline \multirow[b]{2}{*}{$\mathrm{FA}^{2}$} & \multicolumn{2}{|c|}{ Raw milk ${ }^{3}$} & \multirow[b]{2}{*}{$\mathrm{SE}$} & \multirow[b]{2}{*}{$P$-value } \\
\hline & $\begin{array}{c}\text { Control } \\
\text { milk }\end{array}$ & $\begin{array}{l}\text { Treatment } \\
\text { milk }\end{array}$ & & \\
\hline Total fat content, $\%$ & 3.59 & 3.28 & 0.08 & 0.03 \\
\hline \multicolumn{5}{|l|}{$\mathrm{g} / 100 \mathrm{~g}$ of $\mathrm{FA}$} \\
\hline $4: 0$ & 3.99 & 3.56 & 0.14 & 0.08 \\
\hline $6: 0$ & 2.32 & 1.92 & 0.16 & 0.15 \\
\hline $8: 0$ & 1.14 & 0.935 & 0.04 & 0.02 \\
\hline 9:0 & 0.174 & 0.243 & 0.01 & 0.03 \\
\hline 10:0 & 2.28 & 2.02 & 0.33 & 0.58 \\
\hline 11:0 & 0.570 & 0.150 & 0.14 & 0.01 \\
\hline $11: 1$ & 0.251 & 0.304 & 0.10 & 0.63 \\
\hline $12: 0$ & 3.65 & 3.03 & 0.33 & 0.25 \\
\hline $12: 1$ & 0.448 & 0.528 & 0.11 & 0.63 \\
\hline $13: 0$ & 0.282 & 0.284 & 0.07 & 0.98 \\
\hline $14: 0$ & 9.84 & 10.9 & 0.35 & 0.01 \\
\hline $14: 1$ & 0.971 & 1.39 & 0.14 & 0.09 \\
\hline $15: 0$ & 1.09 & 1.33 & 0.20 & 0.36 \\
\hline $16: 0$ & 26.9 & 26.0 & 0.47 & 0.22 \\
\hline $16: 1$ & 1.18 & 1.31 & 0.06 & 0.21 \\
\hline $17: 0$ & 1.03 & 0.719 & 0.18 & 0.21 \\
\hline $18: 0$ & 10.4 & 8.96 & 0.07 & $<0.01$ \\
\hline $18: 1$ total & 21.9 & 21.7 & 0.45 & 0.80 \\
\hline trans-9 18:1 & 0.710 & 1.05 & 0.19 & 0.27 \\
\hline trans-10 18:1 & 1.01 & 1.97 & 0.16 & $<0.01$ \\
\hline trans-11 18:1 & 0.983 & 2.49 & 0.05 & $<0.01$ \\
\hline cis-9 18:1 & 18.4 & 15.4 & 0.45 & $<0.01$ \\
\hline cis-11 18:1 & 0.803 & 0.807 & 0.07 & 0.97 \\
\hline 19:0 & 0.606 & 0.469 & 0.12 & 0.44 \\
\hline $18: 2$ & 2.99 & 2.94 & 0.23 & 0.86 \\
\hline $18: 3 n-6$ & 0.534 & 1.06 & 0.30 & 0.26 \\
\hline $20: 0$ & 0.718 & 1.12 & 0.25 & 0.31 \\
\hline $18: 3 n-3$ & 0.018 & 0.213 & 0.01 & $<0.01$ \\
\hline $20: 1$ & 0.093 & 0.181 & 0.02 & 0.03 \\
\hline Total CLA & 0.575 & 1.60 & 0.08 & $<0.01$ \\
\hline trans- 7, cis-9 + cis-9,trans-11 & 0.021 & 0.111 & 0.01 & $<0.01$ \\
\hline trans -9, cis $-11+$ cis- 10, trans -12 & 0.081 & 0.265 & 0.04 & 0.03 \\
\hline trans-10, cis-12 & 0.120 & 0.287 & 0.03 & 0.01 \\
\hline cis-9,cis-11 & 0.054 & 0.151 & 0.02 & $<0.01$ \\
\hline trans- 11, cis- 13 & 0.052 & 0.142 & 0.02 & 0.03 \\
\hline cis-11,cis-13 & 0.049 & 0.145 & 0.01 & $<0.01$ \\
\hline trans- 11, trans- 13 & 0.086 & 0.109 & 0.03 & 0.61 \\
\hline trans-9,trans-11 & 0.018 & 0.213 & 0.01 & $<0.01$ \\
\hline Other trans peak & 0.093 & 0.181 & 0.02 & 0.03 \\
\hline $20: 2$ & 0.291 & 0.473 & 0.07 & 0.11 \\
\hline $20: 3 n-6$ & 0.479 & 0.835 & 0.22 & 0.30 \\
\hline $20: 3 n-3$ & 0.507 & 0.703 & 0.17 & 0.45 \\
\hline $20: 4$ & 0.483 & 0.808 & 0.13 & 0.15 \\
\hline $22: 0$ & 0.267 & 0.535 & 0.25 & 0.49 \\
\hline $22: 1$ & 0.214 & 0.418 & 0.14 & 0.27 \\
\hline $20: 5(\mathrm{EPA})^{4}$ & 0.280 & 0.297 & 0.10 & 0.90 \\
\hline $22: 2$ & 0.225 & 0.437 & 0.13 & 0.26 \\
\hline $22: 3$ & 1.002 & 0.504 & 0.21 & 0.12 \\
\hline $24: 1$ & 0.208 & 0.147 & 0.09 & 0.59 \\
\hline $22: 4$ & 0.697 & 0.332 & 0.27 & 0.23 \\
\hline $22: 5$ & 0.170 & 0.264 & 0.07 & 0.42 \\
\hline $22: 6(\mathrm{DHA})^{5}$ & 0.375 & 0.506 & 0.17 & 0.61 \\
\hline Short-chain $\mathrm{FA}^{6}$ & 15.1 & 13.0 & $\begin{array}{l}0.11 \\
0.45\end{array}$ & $<0.01$ \\
\hline Medium-chain $\mathrm{FA}^{7}$ & 41.0 & 41.7 & 0.83 & 0.35 \\
\hline Long-chain $\mathrm{FA}^{8}$ & 43.05 & 44.5 & 0.44 & 0.04 \\
\hline \multirow[t]{2}{*}{ SFA } & 65.3 & 62.3 & 0.61 & 0.02 \\
\hline & & & & Contin \\
\hline
\end{tabular}


Table 1 (Continued). Average raw milk FA profile of control and treatment milks ${ }^{1}$

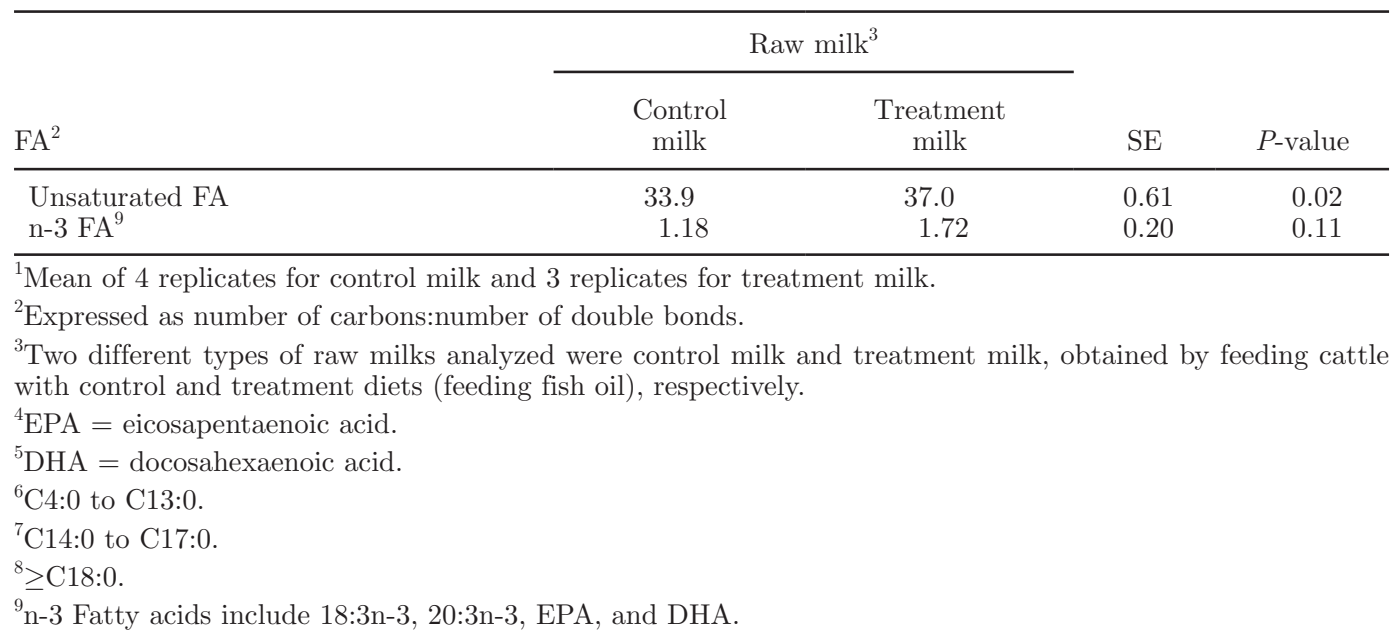

content increased in the treatment milk compared with the control milk. The biggest increase among all the CLA isomers was observed in the trans-9,trans-11 CLA (11.8 times), followed by the trans-7,cis-9 + cis9,trans-11 CLA isomer peak (5.24 times) in treatment milk compared with control milk. In vitro studies on tumor cell lines have indicated the anticarcinogenic effect of cis-9,trans-11 CLA, and trans-10,cis-12 CLA isomers (Chujo et al., 2003; Hubbard et al., 2003). The increase in trans-9,trans-11 CLA and trans-7,cis-9 + cis-9,trans-11 CLA isomers could be associated with the biohydrogenation changes occurring in the rumen of cattle fed fish oil-supplemented diets (Bauman et al., 2006). The increase in the trans-9,trans-11 CLA isomer in milk on extracting FA by the methylation procedure has also been reported recently by Jenkins (2010). The effect of the butylation extraction procedure on isomerization of other CLA isomers to the trans-9,trans-11 CLA isomer is not known. However, the effect might not be as prominent as reported by Jenkins (2010), as the control milk does not show such a high proportion of the trans-9,trans-11 CLA isomer as seen in treatment milk. The overall effect of increase in different CLA isomers was also reflected on the total CLA content, which increased in treatment milk to $1.60 \mathrm{~g} / 100 \mathrm{~g}$ of FA compared with $0.575 \mathrm{~g} / 100 \mathrm{~g}$ of FA in control milk. This corresponds to a 2.8 times increase in the total CLA content in milk of cattle fed the treatment diet supplemented with fish oil compared with the control diet.

Fish oil supplementation of dairy cow diets also increased the concentration of trans-11 C18:1 2.5 times (vaccenic acid, VA) and trans-10 C18:1 1.9 times $(P<0.01)$ in treatment milk compared with control milk. The treatment diet also decreased the oleic acid (cis-9 C18:1) content in milk, but the total C18:1 FA remained unchanged. These changes did not affect the physical properties of milk or the Cheddar cheese produced from the treatment milk. The variations in the trans-11,trans-10 and cis-9 C18:1 isomers further indicate the effect of different biohydrogenation pathways in the rumen. Vaccenic acid is an intermediate of the normal rumen biohydrogenation pathway, producing cis-9,trans-11 CLA as an end product (Shingfield et al., 2006), whereas trans-10 C18:1 is an intermediate product of an alternate biohydrogenation pathway, producing the trans-10,cis-12 CLA isomer (Bauman et al., 2006). Oleic acid can isomerize to the trans C18:1 isomer or hydrogenate to stearic acid (C18:0; Mosley et al., 2002) in the rumen. Stearic acid content, however, decreased with feeding of the treatment diet $(P$ $<0.01)$. Stearic acid is the end product of most of the biohydrogenation pathways in the rumen and tends to decrease in concentration when intermediates such as CLA isomers, VA, and trans-10 C18:1 FA accumulate (Donovan et al., 2000). Thus, the presence of high concentrations of both VA and trans-10 C18:1, and lower concentrations of oleic and stearic acids indicates the possible production of CLA by both normal and alternate biohydrogenation pathways in the rumen of cattle.

A decrease in short-chain FA (SCFA; $P=0.01)$, increase in long-chain FA $(P=0.04)$, lack of variation in medium-chain FA $(P>0.05)$, increase in unsaturated FA (UFA; $P=0.04)$, and decrease in SFA $(P=0.02)$ were observed in milk obtained from cattle fed fish oil-supplemented diets (Table 1). Although the total amount of n-3 FA (C18:3n-3, C20:5n-3, and C22:6n-3) did not change, C18:3n-3 showed a significant increase $(P<0.01)$ in the milk obtained from cattle fed a fish oil-supplemented diet. A similar trend was reported by several studies (Donovan et al., 2000; Whitlock et al., 2002; Bharathan et al., 2008). The UFA in fish oil 
of dietary manipulation studies has been shown to be detrimental to rumen microbiota (AbuGhazaleh and Jenkins, 2004). They reduce the rate of biohydrogenation in the rumen and result in higher concentrations of long-chain FA and UFA in milk, which was observed in the present study.

\section{Cheddar Cheese Analysis}

Composition of Cheddar Cheeses. No variation was observed in fat, protein, fat in DM, and $\mathrm{pH}$ based on the type of milk or the culture used (Table 2). The proximate analysis of the cheeses indicated that the cheeses made using control milk and DVS culture were similar to cheeses made using DVS culture reported in earlier studies (Awad et al., 2005a). The variations observed in moisture and salt content cannot be conclusively related to the type of milk used, as several other factors during the cheesemaking procedure could have induced variations. The $\mathrm{pH}$ of different cheeses over different ripening periods did not vary significantly. Likewise, no consistent pattern of increase or decrease in $\mathrm{pH}$ was discernible when treatment with 2 different cultures and 2 different milk were studied $(P=0.02)$.

Microbiological Counts During Ripening. The M17 agar is specific for Lactococcus spp., whereas the MRS agar is specific for Lactobacillus spp. In spite of the decrease in M17 counts observed in all 4 cheeses during the ripening over 6 mo $(P<0.01)$, the CI4b cheeses had consistently higher M17 counts than cheeses made with control culture (Figure 2; $P<0.01$ ). Similar results were also reported by Pandit (2008), with around $7 \mathrm{log} \mathrm{cfu} / \mathrm{g}$ for CI4b culture compared with $5 \log \mathrm{cfu} / \mathrm{g}$ for DVS culture (M17 counts) in
Cheddar cheeses. The MRS count enumerates mainly Lactobacillus spp., which are the nonstarter lactic acid bacteria (NSLAB). An overall increase was observed in the MRS counts of all the 4 different cheeses with the duration of ripening $(P<0.01)$. Similar trends of lower MRS counts in the initial months of ripening and a gradual increase thereafter have previously been reported (Awad et al., 2005a; Pandit, 2008). In general, CI4b cheeses had higher MRS counts compared with cheeses made with the control culture during 1,3 , and 6 mo of ripening. The decrease in M17 counts with ripening and increase in MRS counts indicate the increase in NSLAB and decrease in starter lactic acid bacteria (SLAB) in cheeses with ripening. The interspecies dynamics of the different microorganisms (starter and nonstarter) present in the ripened cheeses were not investigated in the present study. Madkor et al. (2000) attributed the reduction in starter culture count on ripening to cell autolysis. At the end of 6 mo, the M17 and MRS counts of cheeses made with control culture were quite similar, showing a tendency for the NSLAB and SLAB populations to equilibrate on ripening for 6 mo. Similar equilibration of counts was not observed in the CI4b cheeses (especially cheese made using control milk and CI4b culture), and the SLAB population at the end of 6 mo of ripening remained higher than the NSLAB population. This could be associated with higher rate of growth of the CI4b culture compared with all other lactic acid bacteria present in the cheeses, as evident in the present study.

Sensory Evaluation of Cheddar Cheeses. The overall flavor values of the cheeses were mainly affected by the type of culture used $(P<0.01)$ and age of ripening $(P<0.01$; Table 3$)$. However, no significant varia-

Table 2. Chemical composition and $\mathrm{pH}$ of different treatments of Cheddar cheese ${ }^{1}$

\begin{tabular}{|c|c|c|c|c|c|c|c|c|c|}
\hline \multirow[b]{2}{*}{ Parameter } & \multirow[b]{2}{*}{ Month } & \multicolumn{4}{|c|}{ Cheddar cheese $^{2}$} & \multirow[b]{2}{*}{$\mathrm{SE}$} & \multicolumn{3}{|c|}{$P$-value } \\
\hline & & DVS & CI4b & DVS & CI4b & & Milk & Cult $^{3}$ & Int $^{4}$ \\
\hline Moisture, \% & 1 & 39.37 & 38.11 & 40.18 & 39.57 & 0.58 & 0.04 & 0.06 & 0.46 \\
\hline Fat, $\%$ & 1 & 31.24 & 30.76 & 30.44 & 30.38 & 0.36 & 0.06 & 0.32 & 0.43 \\
\hline Protein, \% & 1 & 22.96 & 24.04 & 23.76 & 23.87 & 0.52 & 0.43 & 0.16 & 0.24 \\
\hline & 3 & 4.91 & 5.00 & 4.97 & 4.89 & & & & \\
\hline & 6 & 4.99 & 4.95 & 4.99 & 4.91 & & & & \\
\hline
\end{tabular}


A

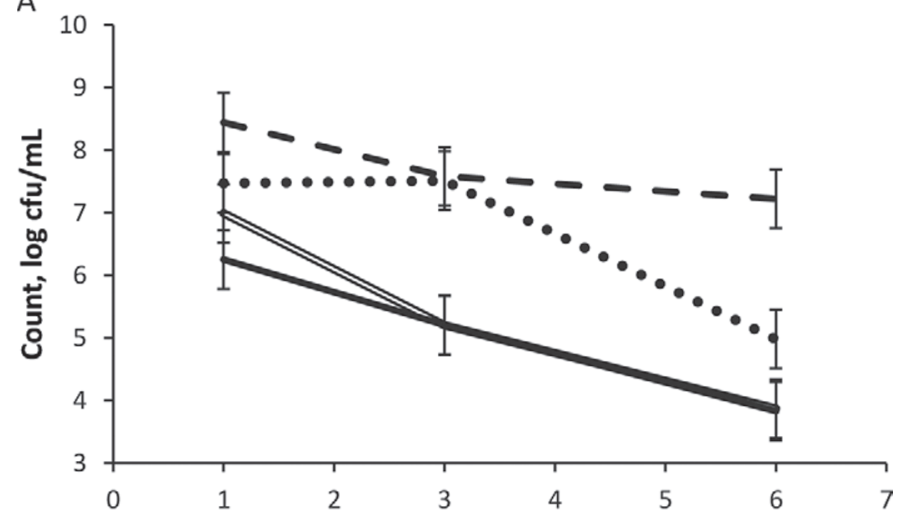

B

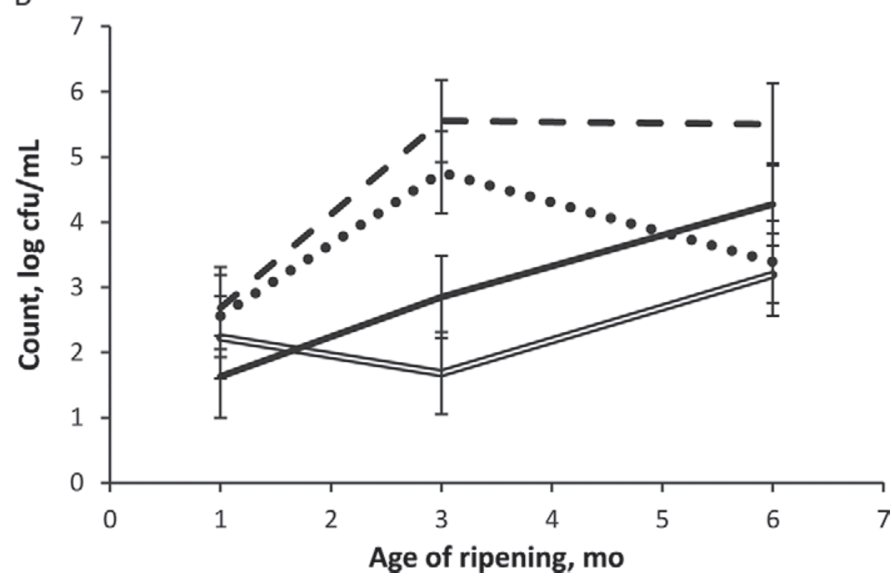

Figure 2. Microbiological counts on (A) M17 and (B) de Man, Rogosa, and Sharpe (MRS) agar in different treatments of Cheddar cheese after 1,3 , and 6 mo of ripening (mean of 3 replicates). The 4 different treatments represented in the graphs are cheese made from control milk with a direct vat set (DVS) culture (double solid lines), control milk with Lactococcus lactis (CI4b) culture (dashed lines), treatment milk (milk obtained after feeding fish oil) with DVS culture (single solid lines), and treatment milk with CI4b culture (dotted lines). The DVS-850 culture (Chr. Hansen Inc., Milwaukee, WI) consisted of Lactococcus lactis ssp. lactis and the CI4b culture was Lactococcus lactis sp.

tion was observed in the acid flavor of different cheeses based on the type of culture used. Slightly higher bitter and unclean flavor was observed for CI4b cheeses $(P<$ 0.01 ), which, however, increased in both cheeses made using the CI4b culture and cheeses made using the control culture, as ripening progressed. The CI4b cheeses were also associated with flat/lacking flavor compared with cheeses made using the control culture $(P=0.03)$. Bitter flavors are usually associated with production of bitter peptides during proteolysis (Madkor et al., 2000). Earlier researchers remedied the production of bitter and unclean flavor using adjunct cultures in cheeses (e.g., Madkor et al., 2000).

The type of culture used did not affect the overall body and texture of cheeses. Ripening induced a slight reduction in the acceptability of the overall body and texture of all cheeses. Similar results have been reported previously by Pandit (2008). Regarding the effect of the type of milk on the texture of cheese, treatment milk decreased the curdy texture significantly $(P<0.01)$, the reason for which is not evident. Curdiness was reduced in all cheeses with ripening $(P<0.01)$. The type of milk or culture used did not affect the crumbly and smooth characteristics of cheese body and texture $(P$ $>0.05$ ), although previous studies using CI4b cultures showed higher crumbliness and shortness compared with cheese made using the DVS-850 culture (Pandit, 2008).

\section{FA Composition of Cheddar Cheese}

CLA Isomeric Profile of Cheeses. Major determinants of the total CLA content in cheese are the type of milk $(P<0.01)$ and type of culture $(P=0.01$; Table 4). Cheese made using treatment milk had 2.1 times more total CLA than that of control milk after 1 mo of ripening. The CI4b cheeses contained 1.1 times higher total CLA (1.75 g/100 g of FA) than cheeses made using the control culture (1. $61 \mathrm{~g} / 100 \mathrm{~g}$ of FA) after the first month of ripening. A similar increase in the CLA content of CI4b cheeses compared with cheeses made using control culture (from 0.62 to $0.86 \mathrm{~g} / 100 \mathrm{~g}$ of FA) was also reported by Pandit (2008), from 0.41 to $1.12 \mathrm{~g} / 100 \mathrm{~g}$ of FA. The CLA isomeric content in cheese (after 1 mo of ripening) was much higher than that reported for raw milk. This could be due to the effect of proteins acting as hydrogen donors, enhancing the CLA content in cheese, as described by Lin et al. (1999). Over the ripening period of 6 mo, CI4b increased the total CLA content in control milk cheese by 1.3 times (1.09 to $1.44 \mathrm{~g} / 100 \mathrm{~g}$ of FA) and in treatment milk cheese by 1.1 times (2.41 to $2.61 \mathrm{~g} / 100 \mathrm{~g}$ of FA), albeit not significantly (except the trans-7,cis-9 + cis-9,trans-11 CLA isomer peak; $P=0.04$ ). The CLA content of CI4b cheese on ripening over 6 mo reported by Pandit (2008) showed an increase from 0.85 to $0.97 \mathrm{~g} / 100 \mathrm{~g}$ of FA during 6 mo of ripening. The DVS culture, however, reduced the total amount of CLA in cheese on ripening for 6 mo by 1.1 times (from 1.61 in the 1 mo-ripened cheese to $1.52 \mathrm{~g}$ of CLA/100 g of FA in the 6 mo-ripened cheese).

The principal determinant of the initial (after 1 mo of ripening) content of different CLA isomers in the cheeses was the source of milk $(P<0.01$; Table 4$)$. The major CLA isomer observed in the cheeses was trans9,trans-11 CLA, which is in contrast to the findings of other studies observing cis-9,trans-11 CLA as the major isomer. The reason for this variation could be the effect of the CLA extraction procedure or the lack of unifor- 
Table 3. Sensory analysis scores for all treatments of Cheddar cheeses ${ }^{1}$

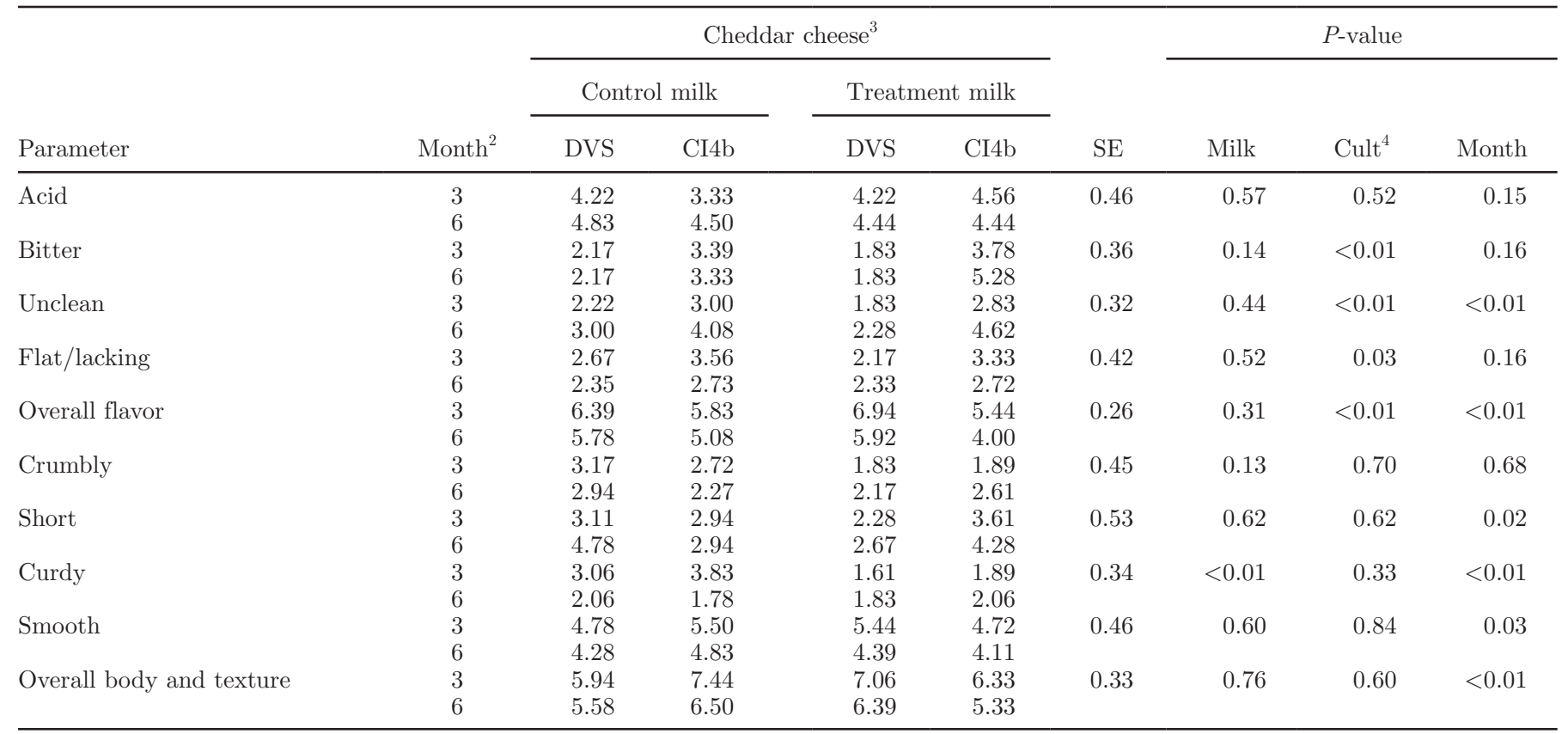

${ }^{1}$ Mean of 3 replicates scored on a 9-point hedonic scale with flavor and body and texture scores of $1=$ none, $5=$ definite, and $9=$ pronounced, and overall flavor and body and texture scores of $1=$ poor, $5=$ average, and $9=$ excellent.

${ }^{2}$ Month $=$ months of ripening.

${ }^{3}$ Four different treatments of Cheddar cheese were cheese made from control milk with direct vat set (DVS) culture, control milk with Lactococcus lactis (CI4b) culture, treatment milk (milk obtained after feeding fish oil) with DVS culture, and treatment milk with CI4b culture.

${ }^{4}$ Culture effect.

mity in the identification of isomers in different studies, as explained by other researchers (Kramer et al., 1999; Jenkins, 2010). Isomers that increased in treatment milk cheeses were trans- 7 , cis-9 + cis-9,trans-11, trans9,cis-11 + cis-10,trans-12, trans-10,cis-12, cis-9,cis-11, cis-11,cis-13, trans-11,trans-13, and trans-9,trans-11 CLA. Control culture (DVS-850) used in cheeses did not alter the content of different CLA isomers during the first 3 mo of ripening. However, some changes were noticed during extended ripening. This may be due to the increase in the population of NSLAB observed for DVS culture cheeses during ripening (Figure 2). An increase in CLA content and an increase in MRS counts during the last 3 mo have been reported by Pandit (2008). Similarly, Coakley et al. (2007) also reported a corresponding increase in the NSLAB population with that of the cis-9,trans-11 CLA isomer. Although the corresponding variations in NSLAB populations and CLA content were observed in those studies, these 2 attributes were not correlated. In effect, further studies need to be conducted to identify the reasons associated with the differential response observed in CLA isomeric content in DVS cheese on extended ripening.

The variations in raw milk FA profile have been shown to affect the FA profile in Cheddar cheese by researchers (Dhiman et al., 1999; Coakley et al., 2007).
These variations can also be thought to affect the activity of cheese cultures, which are mainly lactic acid bacteria. In previous studies, lactic acid bacteria have been reported to utilize different FA, such as oleic, linoleic, ricinoleic, and vaccenic acids, to produce CLA isomers (Lin, 2006). Hence, many of the FA present in the raw milk may act as substrates for production of CLA in cheese by the action of CLA-producing cheese cultures. Slight variations in the CLA content in milk and cheese may be attributed to the processing steps undergone during cheese manufacture (Lin et al., 1999).

In the case of cheese made using treatment milk and CI4b culture, a general decrease in most of the CLA isomeric contents was observed during the first $3 \mathrm{mo}$, and an increase during the later phase of ripening (Table 4). The SLAB population decreased during the first $3 \mathrm{mo}$ and the maximum bacterial count for NSLAB was observed during the third month of ripening (Figure 2). However, cheese made using control milk and CI4b culture exhibited a different trend (Table 4). An increase in the different CLA isomeric content was observed during the first $3 \mathrm{mo}$ of ripening (total CLA content increased from 1.09 to $1.35 \mathrm{~g} / 100$ $\mathrm{g}$ of FA) and a decrease during the remaining 3 mo of ripening (1.35 to $0.99 \mathrm{~g} / 100 \mathrm{~g}$ of $\mathrm{FA}$ ). The decrease in this case cannot be associated with the decrease in 
Table 4. Profile of C18 FA and various FA groups of different treatments of Cheddar cheese ripened for 1, 3, and 6 mo

\begin{tabular}{|c|c|c|c|c|c|c|c|c|c|}
\hline \multirow{3}{*}{$\begin{array}{l}\mathrm{FA},{ }^{2} \\
\mathrm{~g} / 100 \mathrm{~g} \text { of } \mathrm{FA}\end{array}$} & \multirow[b]{3}{*}{ Month $^{3}$} & \multicolumn{4}{|c|}{ Cheddar cheese ${ }^{4}$} & \multirow[b]{3}{*}{$\mathrm{SE}$} & \multirow{2}{*}{\multicolumn{3}{|c|}{$P$-value ${ }^{5}$}} \\
\hline & & \multicolumn{2}{|c|}{ Control milk } & \multicolumn{2}{|c|}{ Treatment milk } & & & & \\
\hline & & DVS & CI4b & DVS & CI4b & & Milk & Cult & Month \\
\hline \multirow[t]{3}{*}{ 18:0 } & 1 & 11.7 & 10.8 & 8.29 & 8.86 & \multirow[t]{3}{*}{0.56} & \multirow[t]{3}{*}{$<0.01$} & \multirow[t]{3}{*}{0.74} & \multirow[t]{3}{*}{0.15} \\
\hline & 3 & 11.3 & 11.1 & 8.81 & 8.34 & & & & \\
\hline & 6 & 9.80 & 10.7 & 8.65 & 8.19 & & & & \\
\hline $18: 1$ total & 6 & 26.0 & 21.3 & 23.1 & 24.0 & & & & \\
\hline trans-9 18:1 & 1 & 0.141 & 0.095 & 0.120 & 0.145 & 0.05 & 0.12 & 0.40 & 0.01 \\
\hline & 3 & 0.193 & 0.227 & 0.218 & 0.173 & & & & \\
\hline & 6 & 0.085 & 0.235 & 0.279 & 0.305 & & & & \\
\hline trans-10 18:1 & 1 & 0.123 & 0.084 & 0.727 & 0.798 & 0.39 & $<0.01$ & 0.97 & 0.71 \\
\hline & 3 & 0.292 & 0.317 & 0.796 & 1.15 & & & & \\
\hline & 6 & 0.102 & 0.134 & 1.07 & 0.675 & & & & \\
\hline & 6 & 24.8 & 19.3 & 14.7 & 14.8 & & & & \\
\hline cis-11 18:1 & 1 & 0.555 & 0.492 & 0.561 & 2.44 & 1.16 & 0.07 & 0.68 & 0.30 \\
\hline & 3 & 0.581 & 0.539 & 0.581 & 0.585 & & & & \\
\hline & 6 & 0.553 & 0.577 & 3.09 & 2.84 & & & & \\
\hline $18: 2$ & 1 & 2.51 & 2.64 & 2.86 & 2.65 & 0.17 & 0.72 & 0.35 & 0.44 \\
\hline & 3 & 2.60 & 2.51 & 2.61 & 2.73 & & & & \\
\hline & 6 & 3.10 & 2.60 & 2.65 & 2.68 & & & & \\
\hline Total CLA & 1 & 1.09 & 1.09 & 2.14 & 2.41 & 0.18 & $<0.01$ & 0.01 & 0.73 \\
\hline & 3 & 1.35 & 1.37 & 2.01 & 2.14 & & & & \\
\hline & 6 & 0.99 & 1.44 & 2.05 & 2.61 & & & & \\
\hline trans -7, cis $-9+$ cis- 9, trans -11 & 1 & 0.108 & 0.111 & 0.180 & 0.191 & 0.03 & $<0.01$ & 0.05 & 0.04 \\
\hline & 3 & 0.161 & 0.158 & 0.182 & 0.251 & & & & \\
\hline & 6 & 0.111 & 0.120 & 0.210 & 0.307 & & & & \\
\hline trans -9, cis- $11+$ cis- 10, trans -12 & 1 & 0.080 & 0.068 & 0.151 & 0.203 & 0.03 & $<0.01$ & 0.19 & 0.80 \\
\hline & 3 & 0.132 & 0.049 & 0.129 & 0.128 & & & & \\
\hline & 6 & 0.043 & 0.116 & 0.106 & 0.174 & & & & \\
\hline cis-11,cis-13 & 1 & 0.077 & 0.069 & 0.126 & 0.209 & 0.03 & $<0.01$ & 0.01 & 0.52 \\
\hline & 3 & 0.074 & 0.111 & 0.165 & 0.181 & & & & \\
\hline & 6 & 0.067 & 0.135 & 0.157 & 0.217 & & & & \\
\hline trans-11,trans- 13 & 1 & 0.090 & 0.095 & 0.157 & 0.152 & 0.02 & $<0.01$ & 0.17 & 0.53 \\
\hline & 3 & 0.120 & 0.163 & 0.131 & 0.136 & & & & \\
\hline & 6 & 0.090 & 0.104 & 0.161 & 0.204 & & & & \\
\hline trans-9,trans-11 & 1 & 0.382 & 0.304 & 0.757 & 0.909 & 0.07 & $<0.01$ & 0.18 & 0.50 \\
\hline & 3 & 0.410 & 0.419 & 0.862 & 0.882 & & & & \\
\hline & 6 & 0.343 & 0.409 & 0.852 & 0.920 & & & & \\
\hline Other trans peak & 1 & 0.089 & 0.102 & 0.340 & 0.217 & 0.06 & 0.10 & 0.91 & 0.23 \\
\hline & 3 & 0.130 & 0.125 & 0.111 & 0.114 & & & & \\
\hline & 6 & 0.115 & 0.187 & 0.114 & 0.176 & & & & \\
\hline Short-chain $\mathrm{FA}^{6}$ & 1 & 13.3 & 14.5 & 12.4 & 12.3 & 0.51 & $<0.01$ & 0.39 & $<0.01$ \\
\hline & 3 & 13.5 & 13.9 & 12.4 & 12.7 & & & & \\
\hline & 6 & 15.4 & 14.3 & 13.8 & 14.4 & & & & \\
\hline Medium-chain $\mathrm{FA}^{7}$ & 1 & 46.1 & 45.6 & 44.4 & 46.1 & 1.34 & 0.74 & 0.66 & 0.32 \\
\hline & 3 & 45.1 & 46.2 & 46.6 & 44.8 & & & & \\
\hline & 6 & 41.9 & 45.7 & 46.3 & 43.8 & & & & \\
\hline
\end{tabular}


Table 4 (Continued). Profile of C18 FA and various FA groups of different treatments of Cheddar cheese ripened for 1,3 , and 6 mo ${ }^{1}$

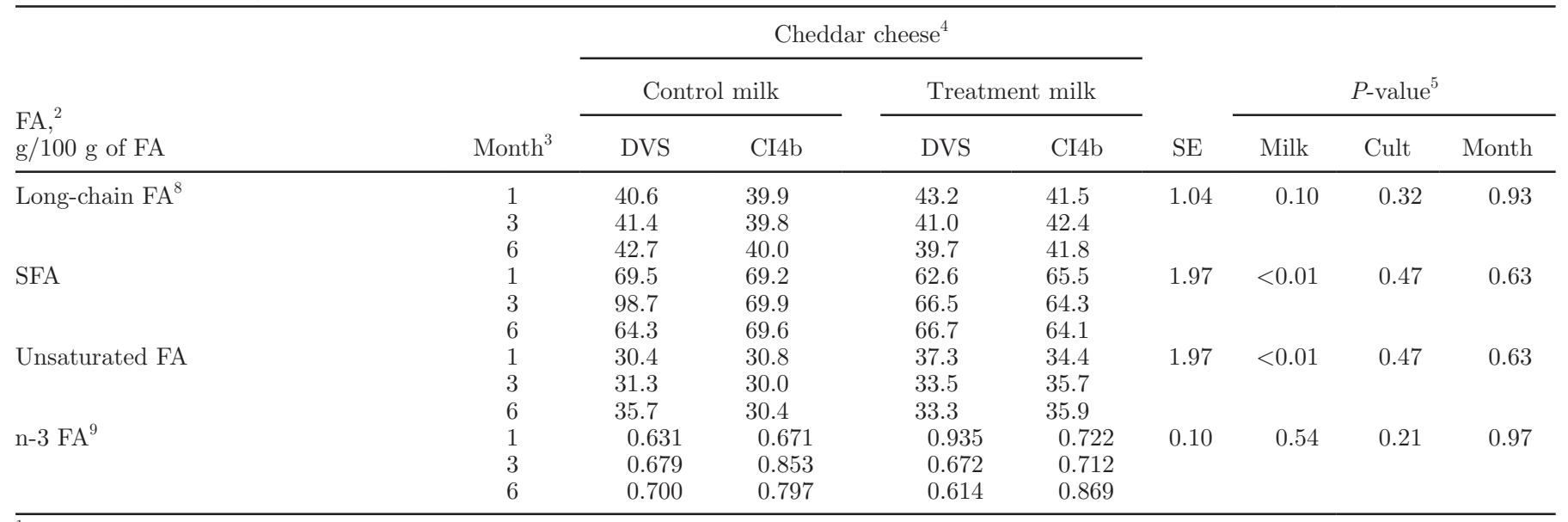

${ }^{1}$ Means of 3 replicates.

${ }^{2}$ Expressed as number of carbons:number of double bonds.

${ }^{3}$ Month $=$ months of ripening.

${ }^{4}$ Four different treatments of Cheddar cheese were cheese made from control milk with direct vat set (DVS) culture, control milk with Lactococcus lactis (CI4b) culture, treatment milk (milk obtained after feeding fish oil) with DVS culture, and treatment milk with CI4b culture.

${ }^{5} P$-values for interactions: milk $\times$ culture effect (Cult): no interactions $(P>0.01)$; milk $\times$ month: cis-9 18:1, cis-9, cis-11 conjugated linoleic acid (CLA), and trans-11,trans-13 CLA $(P<0.01)$; Cult $\times$ month: interactions for trans-11, cis-13 CLA $(P<0.01)$.

${ }^{6} \mathrm{C} 4: 0$ to $\mathrm{C} 13: 0$.

${ }^{7} \mathrm{C} 14: 0$ to $\mathrm{C} 17: 0$.

${ }^{8} \geq \mathrm{C} 18: 0$.

${ }^{9}$ n-3 Fatty acids include 18:3n-3, 20:3n-3, eicosapentaenoic acid (EPA), and docosahexaenoic acid (DHA).

the population of SLAB or increase in the population of NSLAB. These variations can only be attributed to the difference in the availability of FA utilized by SLAB and NSLAB, variation in the availability of these FA in control and treatment milk cheeses, and variation in the NSLAB population. Earlier studies on the ability of lactic acid bacteria to produce FFA during cheese ripening indicated an increase in the population of NSLAB, whereas the population of SLAB remained almost constant. However, these studies have correlated lipolytic activity leading to production of FA only to the SLAB population (Collins et al., 2003).

Cheddar cheese made from treatment milk with CI4b culture (2.61 g of CLA/100 g of FA) contained 2.6 times that of the CLA content in the cheese made from control milk with DVS culture (0.99 g of CLA/100 $\mathrm{g}$ of FA) in 6 mo-ripened cheeses. Thus, based on the per capita consumption of cheese $(43.9 \mathrm{~g} / \mathrm{d}$ per person; USDA, 2008), consumption of enhanced CLA cheese will provide around $0.30 \mathrm{~g}$ of CLA/d. However, in the total diet of a person, intake of CLA from other food products needs to be taken into account as well (estimated normal daily intake is $0.14 \mathrm{~g} / \mathrm{d}$ from different food products in the United States, as referred to by Ritzenthaler et al., 1998), which will provide $0.44 \mathrm{~g}$ of CLA/d. Along with this, if the conversion of VA in the human body is also accounted for (as discussed by Huth et al., 2006), the total CLA content will provide the effective dosage for bestowing anticarcinogenic effects in humans (based on the effective dosage of 0.14 to $0.42 \mathrm{~g} / \mathrm{d}$ ).

Variation in C18:1 FA Isomers. The amount of various C18:1 isomers present in cheeses was also affected by the choice of milk type and the use of CI4b cultures. Treatment milk contained a significantly higher amount of trans-10 and trans-11, and lower amounts of cis-9 (oleic acid) C18:1 isomers compared with control milk (Table 1). A similar trend was discernible for cheeses made from treatment milk after the first month of ripening. Over the 6-mo ripening period, a differential response was observed. An increase was observed in oleic acid content during the first 3 mo of ripening, and a subsequent decrease was observed over the final 3 mo of ripening in cheese made from treatment milk. These differences in trends can also be correlated to the increase in NSLAB during the first 3 mo of ripening in CI4b cheeses, although no previous studies exist in this regard (Figure 2). The presence of a mixture of microorganisms in the later stages of ripening could be responsible for several biohydrogenation, isomerization, and desaturation reactions to take place concurrently (Kishino et al., 2002; Mosley et al., 2002; Lin, 2006).

Other FA Groups. The amount of SCFA was significantly lower in the case of treatment milk cheeses after $1 \mathrm{mo}$ of ripening $(P<0.01 ; 12.3 \mathrm{~g} / 100 \mathrm{~g}$ of FA 
for treatment cheese compared with $13.9 \mathrm{~g} / 100 \mathrm{~g}$ of FA for control cheese). A similar trend was observed in the raw milk samples of treatment milk compared with control milk (Table 1). At the end of the 6 -mo ripening, the SCFA increased $(P<0.01)$. The amount of SFA decreased in treatment cheeses after 1 mo of ripening $(64.0 \mathrm{~g} / 100 \mathrm{~g}$ of FA) compared with the control cheese $(69.3 \mathrm{~g} / 100 \mathrm{~g}$ of FA; $P<0.01)$. A similar decrease was noted for treatment milk (Table 1). The CI4b cheeses did not show any decrease in SFA compared with cheeses made with the control culture over the ripening period. The amount of UFA was significantly higher in treatment cheeses $(35.8 \mathrm{~g} / 100 \mathrm{~g}$ of $\mathrm{FA})$ compared with $30.6 \mathrm{~g} / 100 \mathrm{~g}$ of FA for control cheeses. This may be attributed to the carryover effect from the treatment and control milks. The total UFA remained the same over ripening for CI4b cheeses. However, cheeses made with the control culture showed differential changes, albeit not significant. This can be postulated to be due to the various interactions of the NSLAB population in the cheeses with the SLAB on the utilization of different FA substrates for the production of FFA, including CLA. The higher NSLAB population indicates the presence of a mixture of microorganisms in cheese made from control milk with CI4b culture, which can again be associated with these variations (Kishino et al., 2002; Mosley et al., 2002; Lin, 2006).

\section{CONCLUSIONS}

Our results indicate that feeding the treatment (fish oil-supplemented) diet to cattle resulted in production of milk (treatment milk) with higher CLA content than that from control milk obtained from feeding the control diet $(0.575$ and $1.60 \mathrm{~g} / 100 \mathrm{~g}$ of FA in control and treatment milks, respectively). Eventually the combination of manipulating the cattle diet and CLA-producing starter culture also proved to be an effective method for enhancing the CLA content in cheeses. This was evident from the 2.6-times increase in CLA content of Cheddar cheese made with CLA-producing culture (CI4b culture) and milk from cattle fed fish oil-supplemented diets $(2.61 \mathrm{~g}$ of CLA/100 $\mathrm{g}$ of FA) compared with cheese made using CLA nonproducing culture (DVS) and milk from cattle fed normal diets (0.99 g of CLA/100 g of FA) in 6-mo ripened cheeses. The observed increases in the CLA and C18:1 isomers were associated with alternate biohydrogenation (mainly producing trans-10 C18:1 and trans-10,cis-12 CLA isomers as intermediates), and normal biohydrogenation pathways (producing principally the cis-9,trans-11 CLA and trans-11 C18:1 isomers). In the future, more research is warranted to identify the FA substrates utilized and conversion pathways for specific microbial cultures. This information can enable addition of the specific FA substrates that can be utilized by the cultures used in dairy products to further increase their CLA content. The necessity to study the effect of further processing of milk on the CLA isomers in enhanced CLA cheese also is evident, as there is lack of firm evidence of the effect of heating and other processing steps on CLA. Further studies are required to improve the flavor properties of such CLAenhanced cheeses by using mixed starter cultures and adjunct cultures.

\section{ACKNOWLEDGMENTS}

The funding source for the research assistantship was the US Department of Agriculture (USDA) higher education challenge grant. The assistance of the staff at the South Dakota State University (SDSU) Dairy Research and Training Facility (Brookings) in formulating the cattle diets, feeding the dairy cows, and helping in the milk collections is greatly appreciated.

\section{REFERENCES}

Abdelqader, M. M., A. R. Hippen, K. F. Kalscheur, D. J. Schingoethe, K. Karges, and M. L. Gibson. 2009. Evaluation of corn germ from ethanol production as an alternative fat source in dairy cow diets. J. Dairy Sci. 92:1023-1037.

AbuGhazaleh, A. A., and T. C. Jenkins. 2004. Disappearance of docosahexaenoic and eicosapentaenoic acids from cultures of mixed ruminal microorganisms. J. Dairy Sci. 87:645-651.

Andrade, J. C., K. Ascenção, P. Gullón, S. M. S. Henriques, J. M. S. Pinto, T. A. P. Rocha-Santos, A. C. Freitas, and A. M. Gomes. 2012. Production of conjugated linoleic acid by food-grade bacteria: A review. Int. J. Dairy Tech. 65:467-481. http://dx.doi. org/10.1111/j.1471-0307.2012.00871.x.

AOAC International. 2006. Official Methods of Analysis. 18th ed. AOAC International, Gaithersburg, MD.

Awad, S., A. N. Hassan, and F. Halaweish. 2005a. Application of exopolysaccharide-producing cultures in reduced-fat Cheddar cheese: Composition and proteolysis. J. Dairy Sci. 88:4195-4203.

Awad, S., A. N. Hassan, and K. Muthukumarappan. 2005b. Application of exopolysaccharide-producing cultures in reduced-fat Cheddar cheese: Texture and melting properties. J. Dairy Sci. 88:4204-4213.

Bauman, D. E., I. H. Mather, R. J. Wall, and A. L. Lock. 2006. Major advances associated with the biosynthesis of milk. J. Dairy Sci. 89:1235-1243.

Benjamin, S., and F. Spener. 2009. Conjugated linoleic acids as functional food: An insight into their health benefits. Nutr. Metab. (Lond.) 6:36-49.

Bharathan, M., D. J. Schingoethe, A. R. Hippen, K. F. Kalscheur, M. L. Gibson, and K. Karges. 2008. Conjugated linoleic acid increases in milk from cows fed condensed corn distillers solubles and fish oil. J. Dairy Sci. 91:2796-2807.

Campbell, W., M. A. Drake, and D. K. Larick. 2003. The impact of fortification with conjugated linoleic acid (CLA) on the quality of fluid milk. J. Dairy Sci. 86:43-51.

Chin, S. F., W. Liu, J. M. Storkson, Y. L. Ha, and M. W. Pariza. 1992. Dietary sources of conjugated dienoic isomers of linoleic acid, a newly recognized class of anticarcinogens. J. Food Comp. Anal. 5:185-197.

Chujo, H., M. Yamasaki, S. Nou, N. Koyanagi, H. Tachibana, and K. Yamada. 2003. Effects of conjugated linoleic acid isomer on growth factor-induced proliferation of human breast cancer cells. Cancer Lett. 202:81-87. 
Coakley, M., E. Barrett, J. J. Murphy, R. P. Ross, R. Devery, and C. Stanton. 2007. Cheese manufacture with milk with elevated conjugated linoleic acid levels caused by dietary manipulation. J. Dairy Sci. 90:2919-2927.

Collins, Y. F., P. L. H. McSweeney, and M. G. Wilkinson. 2003. Evidence for a relationship between autolysis of starter bacteria and lipolysis in Cheddar cheese. J. Dairy Res. 70:105-113.

Dhiman, T. R., E. D. Helmink, D. J. McMahon, R. L. Fife, and M. W. Pariza. 1999. Conjugated linoleic acid content of milk and cheese from cows fed extruded oilseeds. J. Dairy Sci. 82:412-419.

Donovan, D. C., D. J. Schingoethe, R. J. Baer, J. Ryali, A. R. Hippen, and S. T. Franklin. 2000. Influence of dietary fish oil on conjugated linoleic acid and other fatty acids in milk fat from lactating dairy cows. J. Dairy Sci. 83:2620-2628.

Eulitz, K., M. P. Yurawecz, N. Sehat, J. Fritsche, J. A. G. Roach, M. M. Mossoba, J. K. G. Kramer, R. O. Adlof, and Y. Ku. 1999 Preparation, separation, and confirmation of the eight geometrical cis/trans conjugated linoleic acid isomers 8,10- through 11,13-18:2. Lipids 34:873-877.

Hooi, R., D. M. Barbano, R. L. Bradley, D. Budde, M. Bulthaus, M. Chettiar, J. Lynch, and R. Reddy. 2004. Chemical and physical methods. Pages 363-536 in Standard methods for the examination of dairy products. H. M. Wehr, and J. F. Frank, ed. American Public Health Association (APHA), Washington, DC.

Hubbard, N. E., D. Lim, and K. L. Erickson. 2003. Effects of separate conjugated linoleic acid isomers on murine mammary tumorigenesis. Cancer Lett. 190:13-19.

Huth, P. J., D. B. DiRienzo, and G. D. Miller. 2006. Major scientific advances with dairy foods in nutrition and health. J. Dairy Sci. 89:1207-1221.

Jenkins, T. C. 2010. Common analytical errors yielding inaccurate results during analysis of fatty acids in feed and digesta samples. J. Dairy Sci. 93:1170-1174.

Kishino, S., J. Ogawa, A. Ando, Y. Omura, and S. Shimizu. 2002 Ricinoleic acid and castor oil as substrates for conjugated linoleic acid production by washed cells of Lactobacillus plantarum. Biosci. Biotechnol. Biochem. 66:2283-2286.

Kramer, J. K. G., C. Cruz-Hernandez, Z. Deng, J. Zhou, G. Jahreis, and M. E. R. Dugan. 2004. Analysis of conjugated linoleic acid and trans 18:1 isomers in synthetic and animal products. Am. J. Clin. Nutr. 79(Suppl.):1137S-1145S.

Kramer, J. K. G., N. Sehat, J. Fritsche, M. M. Mossoba, K. Eulitz, M. P. Yurawecz, and Y. Ku. 1999. Separation of conjugated fatty acid isomers. Pages 83-109 in Advances in Conjugated Linoleic Acid Research. Vol. 1. M. P. Yurawecz, M. M. Mossoba, J. K. G. Kramer, M. W. Pariza, and G. J. Nelson, ed. Am. Oil Chem. Soc. Press, Champaign, IL.

Lin, H., T. D. Boylston, L. O. Luedecke, and T. D. Shultz. 1999. Conjugated linoleic acid content of Cheddar type cheeses as affected by processing. J. Food Sci. 64:874-878.

Lin, T. Y. 2006. Conjugated linoleic acid production by cells and enzyme extract of Lactobacillus delbrueckii ssp. bulgaricus with additions of different fatty acids. Food Chem. 94:437-441.

Madkor, S. A., P. S. Tong, and M. El Soda. 2000. Ripening of Cheddar cheese with added attenuated adjunct cultures of Lactobacilli. J. Dairy Sci. 83:1684-1691.
Mosley, E. E., G. L. Powell, M. B. Riley, and T. C. Jenkins. 2002 Microbial biohydrogenation of oleic acid to trans isomers in vitro. J. Lipid Res. 43:290-296.

Mushtaq, S., E. H. Mangiapane, and K. A. Hunter. 2010. Estimation of cis-9, trans-11 conjugated linoleic acid content in UK foods and assessment of dietary intake in a cohort of healthy adults. Br. J. Nutr. 103:1366-1374.

Ogawa, J., S. Kishino, A. Ando, S. Sugimoto, K. Mihara, and S. Shimizu. 2005. Production of conjugated fatty acids by lactic acid bacteria. J. Biosci. Bioeng. 100:355-364.

Pandit, A. 2008. Chapters 2 and 3 in Development of Cheddar Cheese with Enhanced Conjugated Linoleic Acid by Lactic Acid Bacteria. South Dakota State University, Brookings.

Pandit, A., S. Anand, K. Kalscheur, and A. Hassan. 2012. Production of conjugated linoleic acid by lactic acid bacteria in milk without any additional substrate. Int. J. Dairy Tech. 65:603-608. http:// dx.doi.org/10.1111/j.1471-0307.2012.00870.x.

Ritzenthaler, K., M. K. McGuire, R. Falen, T. D. Shultz, and M. A. McGuire. 1998. Estimation of conjugated linoleic acid (CLA) intake. FASEB J. 12:A527.

Rodríguez-Alcalá, L. M., T. Braga, F. Xavier Malcata, A. Gomes, and J. Fontecha. 2011. Quantitative and qualitative determination of CLA produced by Bifidobacterium and lactic acid bacteria by combining spectrophotometric and $\mathrm{Ag}^{+}$-HPLC techniques. Food Chem. 125:1373-1378.

Sehat, N., J. K. G. Kramer, M. M. Mossoba, M. P. Yurawecz, J. A. G Roach, K. Eulitz, K. M. Morehouse, and Y. Ku. 1998. Identification of conjugated linoleic acid isomers in cheese by gas chromatography, silver ion high performance liquid chromatography and mass spectral reconstructed ion profiles, comparison of chromatographic elution sequence. Lipids 33:963-971.

Shantha, N. C., L. N. Ram, J. O'Leary, C. L. Hicks, and E. A. Decker. 1995. Conjugated linoleic acid concentrations in dairy products as affected by processing and storage. J. Food Sci. 60:695-697.

Shingfield, K. J., P. Kairenius, A. Ärölä, D. Paillard, S. Muetzel, S. Ahvenjärvi, A. Vanhatalo, P. Huhtanen, V. Toivonen, J. M. Griinari, and R. J. Wallace. 2012. Dietary fish oil supplements modify ruminal biohydrogenation, alter the flow of fatty acids at the omasum, and induce changes in the ruminal Butyrivibrio population in lactating cows. J. Nutr. 142:1437-1448.

Shingfield, K. J., C. K. Reynolds, G. Hervás, J. M. Griinari, A. S. Grandison, and D. E. Beever. 2006. Examination of the persistency of milk fatty acid composition responses to fish oil and sunflower oil in the diet of dairy cows. J. Dairy Sci. 89:714-732.

USDA (US Department of Agriculture). 2008. Economic Research Service. Accessed Oct. 2010. http://www.ers.usda.gov.

Van Soest, P. J., J. B. Robertson, and B. A. Lewis. 1991. Methods for dietary fiber, neutral detergent fiber, and nonstarch polysaccharides in relation to animal nutrition. J. Dairy Sci. 74:3583-3597.

Whitlock, L. A., D. J. Schingoethe, A. R. Hippen, K. F. Kalscheur, R J. Baer, N. Ramaswamy, and K. M. Kasperson. 2002. Fish oil and extruded soybeans fed in combination increase conjugated linoleic acids in milk of dairy cows more than when fed separately. J. Dairy Sci. 85:234-243. 